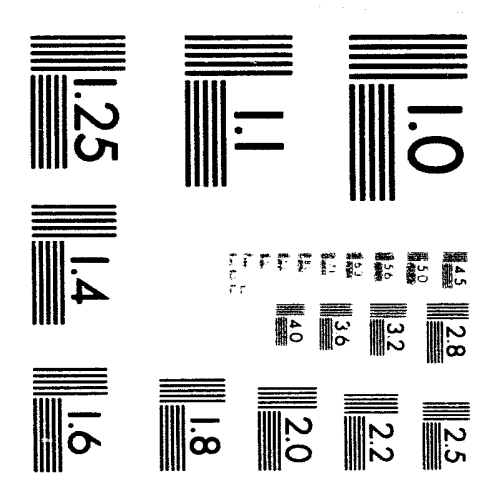



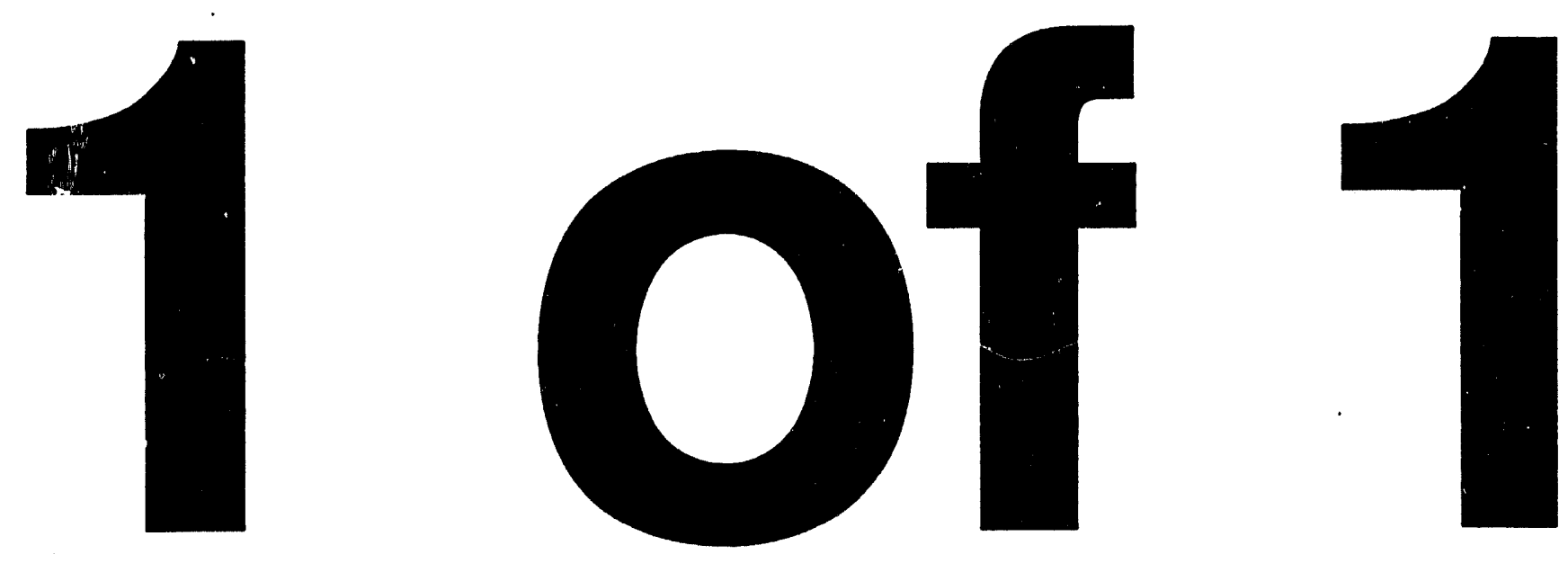


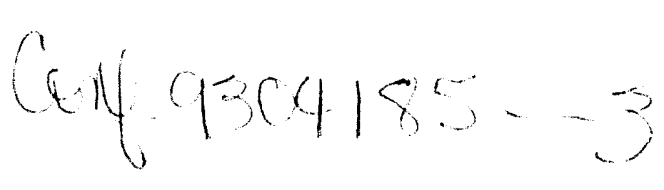

\title{
Monte Carlo Track-Structure Calculations for Aqueous Solutions Containing Biomolecules
}

\author{
J. E. Turner, R. N. Hamm, R. H. Ritchie, and Wesley E. Bolch
}

\section{Abstract}

Detailed Monte Carlo calculations provide a powerful tool for understanding mechanisms of radiation damage to biological molecules irradiated in aqueous solution. This paper describes the computer codes, OREC and RADLYS, which have been developed for this purpose over a number of years. some results are given for calculations of the irradiation of pure water. Comparisons are presented between computations for liquid water and water vapor. Detailed calculations of the chemical $y$ ields of several products from $x$-irradiated, oxygen-free glycylglycine solutions have been performed as a function of solute concentration. Excellent agreement is obtained between calculated and measured yields. The Monte Carlo analysis provides a complete mechanistic picture of pathways to observed radiolytic products. This approach, successful with glycylglycine, will be extended to study the irradiation of oligonucleotides in aqueous solution.

\section{Monte Carlo Approach}

The objective of this work is to develop and apply a computer model of events that take place from the time radiation interacts in an aqueous solution until measurable

"Research sponsored by the office of Health and Environmental Research, U.S. Department of Energy under contract DE-AC05-840R21400 with the Martin Marietta Energy Systems, Inc., in the Health Sciences Research Division at the Oak Ridge National Laboratory, P. O. Box 2008, Oak Ridge, TN 37831-6123.

'Dept. of Nucl. Engineering, Texas A\&M University, College station, $\mathrm{TX} 77843$.

The submirted menuecript hes bee outhored by a contrector of the U.? Government under contract No. DE ACO5-640R2 1400. Acocordingty. the U.S Government reteine a nonsexchuein rovatry-free licenes to putisien of reproduc the oubliahed form of this contribution, c blow others to do so. for U.S. Govemmer purposes." 
radiolytic products are formed. For the highly transient conditions produced within the tracks of charged particles, Monte Carlo procedures are ideally suited to simulate what actually happens. The task can be carried out to the extent that relevant cross sections and interaction mechanisms are known. Since there is only incomplete knowledge of these factors, the Monte Carlo simulation can be used to test various hypotheses. In this way it becomes an important and effective tool for studying radiation-damage mechanisms to biological molecules. Predicted results can be compared with measurements, and the simulation can suggest new experiments. Agreement with measured data is a necessary, but not sufficient, condition for establishing the validity of the model and its inherent assumptions. However, successful testing against a wide variety of measurements under different conditions adds confidence in its essential correctness and usefulness.

\section{Calculations for Liquid water with OREC}

Calculations with OREC start with a specific type of primary charged particle, having a given initial position and velocity in a liquid-water medium. A flight distance is selected for the location of the first collision, based on the total inverse mean free path for inelastic and elastic scattering. Numerical values for the inverse mean free paths, as well as all other numerical data, are based on a 
combination of measurements, where available, and theory. These extensive input data to the code are under continuing review and revision as further studies of details are conducted. Given the site of collision, the code then selects a type of interaction, elastic or inelastic. If the latter, then a choice is made between excitation and ionization; and a transition between specific quantum states is assigned. Algorithms have been developed to treat all possibilities and provide explicitly the residual state of the water molecule and the momentum eigenstate of the scattered primary particle as well as that of the secondary electron, when ionization occurs. All secondary electrons are transported until their energies drop below the assumed threshold of $7.4 \mathrm{eV}$ for electronic transitions in liquid water. To simulate the transport of the primary particle, this process can be repeated until its energy is degraded below threshold; and the entire track is thus generated.

In OREC the passage of a primary charged particle thus leaves in its wake an array of ionized and excited water molecules, $\mathrm{H}_{2} \mathrm{O}^{+}$and $\mathrm{H}_{2} \mathrm{O}^{*}$, in explicit quantum states and subexcitation electrons, $e^{-}$sub, with specified energies $<7.4 \mathrm{ev}$. This array is formed very rapidly $\left(\leq 10^{-15} \mathrm{~s}\right)$ over several hundred angstroms in the track of the primary particle. Starting at $10^{-15} \mathrm{~s}$, the computer code RADLYS, also using Monte Carlo techniques, then simulates the development of the track through the prechemical $\left(10^{-15} \mathrm{~s}\right.$ to $\left.10^{-12} \mathrm{~s}\right)$ and 


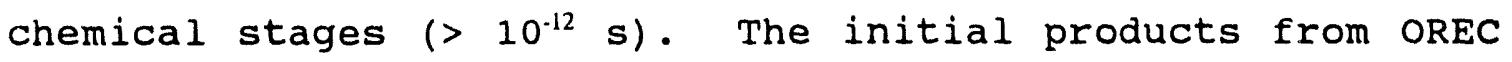
give rise to the following chemical species: $\mathrm{OH}, \mathrm{H}, \mathrm{H}_{3} \mathrm{O}^{+}, \mathrm{e}_{\text {aq }}$, and $\mathrm{H}_{2}$, where $\mathrm{e}_{\mathrm{aq}}$ denotes the hydrated electron. The passage of the primary particle and all secondary electrons thus resuits in a spatial array of these species at the time $10^{-12}$ s. The identity and position of each species, as determined by Monte Carlo procedures, is known explicitly. starting at $10^{-12} \mathrm{~s}$, RADLYS then simulates the further passage of time by random walk (diffusion) of the individual reactants and their possible reactions with one another (e.g., $\mathrm{OH}+\mathrm{H} \rightarrow \mathrm{H}_{2} \mathrm{O}, \mathrm{OH}+$ $\mathrm{OH} \rightarrow \mathrm{H}_{2} \mathrm{O}_{2}$, etc.) or with solute molecules, if present. Details of the code are given in several publications. ${ }^{(1-5)}$

Figure 1 shows an example of a complete track calculated with OREC and RADLYS for a $4-\mathrm{keV}$ electron, which starts moving upward from the origin of the coordinate axes. Each dot represents the position of one of the active radiolytic species. The results of diffusion and intratrack reactions can be seen at the four times shown. The number of reactants decreases from 924 at $10^{-12} \mathrm{~s}$ to 403 at $10^{-7} \mathrm{~s}$, after which relatively few additional reactions occur. Such calculations provide an explicit representation of the chemical development within a charged-particle track in water. One obtains some understanding of the distances over which different parts of a track can affect one another and the times at which details of track structure tend to become unimportant. 
Comparison with Measurements

Calculations such as those represented by Fig. 1 also provide quantitative chemical yields of the radiolytic species as functions of time. As shown in Fig. 2, the time-dependent yields of $e_{a q}$ and $\mathrm{OH}$ have been determined experimentally for water from pulse radiolysis with high-energy electrons.(6-8) -These measured values played a key role in the development of OREC and RADLYS, particularly in formulating the hydration/thermalization algorithms for subexcitation electrons and in the channeling of excited states into different species from $10^{-15} \mathrm{~s}$ to $10^{-12} \mathrm{~s}$. As pointed out above, agreement of calculated results with such data is a necessary condition for the simulation to be valid, but does not constitute verification of the model.

Calculations have also been performed of the Fricke dosimeter yield for tritium beta particles. The computed and measured yields agree.

As described in more detail below, we have carried out extensive calculations and measurements for glycylglycine irradiated in aqueous solution. In these studies, the calculated yields of a number of radiolytic products as functions of solute concentration are found to be in excellent agreement with the measured values. 
We are presently conducting a detailed study of the extensive experimental data collected by LaVerne and Pimblott. ${ }^{(9)}$ These data provide time-dependent yields for radicals and molecular products from water irradiated by electrons. Demonstrating agreement between the results of calculations and this considerable body of data would add significantly to confidence in the code.

In summary, results from OREC and RADLYS have been and are being compared with available experimental data. In addition, the basic assumptions and numerical values used in the code are under continuing study and are subject to revision in the light of new information.

\section{Comparison of Calculations for Liquid Water and Water Vapor}

Several Monte Carlo computer codes have been developed for charged-particle transport in water vapor, for which much more extensive experimental data exist than for the liquid. Comparisons of detailed calculations for the two states of condensation offer a valuable opportunity to gain further understanding of the physics simulated by the codes. We have conducted a number of studies with H. G. Paretzke to compare his vapor code, MOCA, with OREC. ${ }^{(10-12)}$ 
The total inelastic and ionization inverse mean free paths (IMFP) in the two codes are shown in Fig. 3 for electrons with energies up to $10 \mathrm{keV}$. The partitioning of the total inelastic IMFP into ionization and excitation cross sections, $\sigma_{i o n}$ and $\sigma_{\text {exc }}$, is shown in Fig. 4. At energies above a few tens of $\mathrm{eV}$, ionization contributes over $90 \%$ to the inelastic IMFP in the Iiquid, compared with 60-70\% in the vapor. This large difference contributes to the substantially smaller value of the average energy needed to produce an ion pair: $W \sim 22 \mathrm{eV} / \mathrm{ip}$ estimated for the liquid as compared with $\mathrm{W}=33 \mathrm{eV} / \mathrm{ip}$ measured and calculated for the vapor. An additional contribution (in the same direction) to the difference in $W$ values is made by the relatively harder single-collision spectrum for energy loss in the liquid. A comparison of these spectra for $5-\mathrm{keV}$ electrons in the two phases is provided in Fig. 5. The trend of the differences is the same except at very low energies.

The liquid/vapor differences discussed here pertain to the initial, physical stage of the electron-water interaction, at $10^{-15} \mathrm{~s}$. Such differences could affect the subsequent chemical development of a track (e.g., by using RADLYS) . Implied differences in the later chemistry can be illustrated by comparing the frequency distribution for nearest neighbors of all inelastic events in tracks, as shown in Fig. 6 for 100$\mathrm{eV}$ and $1-\mathrm{keV}$ electrons. (The curves for $10-\mathrm{keV}$ electrons are almost the same as for $1-\mathrm{keV}$ electrons). At both energies, 
the most probable nearest-neighbor separation is about $0.6 \mathrm{~nm}$ in the liquid, compared with only about $0.1-0.2 \mathrm{~nm}$ in the vapor. This difference is due principally to the presence of collective effects in the liquid. Collective action, which is absent in the vapor, results in a non-localization of events when energy losses are $\leq 50 \mathrm{eV},{ }^{(12)}$ resulting in a greatly diminished probability for finding two neighboring events as close together in the liquid as in the vapor. The curve marked "NN" in Fig. 6 was calculated with the collective effects "turned off" in OREC. It shows that other substantial differences, like those already mentioned, exist in the codes for the liquid and vapor. The different distributions, such as those shown in the figure, would lead to different chemical development within the electron tracks and to different product yields.

\section{Track structures on a Biomolecular scale}

Figure 7 shows a track segment of a $1-\mathrm{MeV}$ proton in liquid water. Each dot shows the location of an $\mathrm{OH}, \mathrm{H}, \mathrm{e}_{4 q}$, or $\mathrm{H}_{3} \mathrm{O}^{+}$ radical at $10^{-12} \mathrm{~s}$ after passage of the proton, the time at which diffusion-controlled intratrack reactions begin in RADLYS. The lower segment shows the middle portion of the track on an enlarged scale. The distribution of the reactants in groups, or spurs, is clearly evident. 
In Fig. 8, the middle portion of the proton track is displayed on a still larger scale superimposed on a doublehelical array of dots. The array corresponds approximately to the positions of successive bases and sugars of DNA along a cylinder with a diameter of $2 \mathrm{~nm}$. The densities of the reactants along the track and the reaction sites on the DNA are comparable in this example, in which the proton LET $=28$ $-\mathrm{keV} / \mu \mathrm{m}$. BY contrast, LET $=4.8 \mathrm{keV} / \mu \mathrm{m}$ for a $10-\mathrm{MeV}$ proton, $240 \mathrm{keV} / \mu \mathrm{m}$ for a $1-\mathrm{MeV}$ alpha particle, and $4.3 \mathrm{keV} / \mu \mathrm{m}$ for a 100-keV electron. Thus, the density of reactants in the water can be comparable to, or much less than or much greater than the density of reaction sites in DNA, depending on the type of particle and its energy. Also, a charged particle can traverse the DNA structure itself with a high or low probability of producing a quantum transition there (direct effects), depending on these factors.

studies to Link Physical Interactions to Mechanisms of Radiation Damage to Biomolecules

The RADLYS computer code has been extended to study the action of biological molecules in aqueous solution, with and without the presence of dissolved oxygen. As with pure water, the Monte Carlo technique is aptly suited to the simulation of the transient, non-equilibrium conditions and intratrack chemical changes that occur. As a test case of the feasibility of such a study, we investigated the photon 
irradiation of the dipeptide, glycylglycine, in oxygen-free aqueous solution. This molecule was chosen because of its relative simplicity and because the chemical yields of a number of radiojytic products had been measured and interpreted by Garrison and coworkers. ${ }^{(13,14)}$ At the same time as we began the theoretical studies, we started a laboratory program to provide experimental measurements of yields. Calculations were performed for the same conditions of solute concentration, photon energy spectrum, dose rate, and other factors under which the measurements were made. ${ }^{(15)}$

The structure of the glycylglycine molecule is shown by the formula

$$
(\mathrm{GLY})_{2}=\mathrm{NH}_{3}{ }^{+} \mathrm{CH}_{2} \mathrm{CONHCH}_{2} \mathrm{COO} \text {. }
$$

When irradiated in solution at concentrations not exceeding $\sim 1 \mathrm{M}$, the direct action of radiation on the molecule itself is necligible. The radiolytic products of water attack the molecule with the following initiating reactions:

$$
\begin{aligned}
& \mathrm{e}_{\text {aq }}^{-}+(\mathrm{GLY})_{2} \rightarrow \mathrm{NH}_{3}{ }^{+}+\dot{\mathrm{CH}}_{2} \mathrm{CONHCH}_{2} \mathrm{COO}^{-} \\
& \mathrm{OH}+(\mathrm{GLY})_{2} \rightarrow \mathrm{NH}_{3}{ }^{+} \mathrm{CH}_{2} \mathrm{CONHCHCOO}+\mathrm{H}_{2} \mathrm{O} \\
& \mathrm{H}+(\mathrm{GLY})_{2} \rightarrow \mathrm{NH}_{3}{ }^{+} \mathrm{CH}_{2} \mathrm{CONHCH} \mathrm{HCOO}+\mathrm{H}_{2} .
\end{aligned}
$$


The resulting peptide radicals react with one another, and the deamination radical also reacts with the solute. A number of detailed reaction pathways, postulated by Garrison and coworkers, ${ }^{(14)}$ were simulated in the RADLYs code. Explicit computations were carried out for the yields of free ammonia, total ammonia (following hydrolysis of some products), acetylglycine, diaminosuccinic acid, aspartic acid, and succinic acid as functions of glycylglycine concentration between $0.05 \mathrm{M}$ and $1.0 \mathrm{M}$. The yields were both measured and calculated for $250-\mathrm{kV}$ X rays, delivered at a dose rate of $2.80 \mathrm{~Gy} / \mathrm{min}$ in oxygen-free solutions. Results of the measurements and calculations are shown in Fig. 9, where the agreement is very good. As found in the calculations and observed experimentally, the yields of aspartic and succinic acids decrease with increasing solute concentration, while the reverse is true for the other products. This is attributed to the fact that the deamination radical is a precursor to the former two, and it is scavenged by the solute.

As mentioned above, the Monte Carlo simulation furnishes a detailed picture of events as they are thought to occur in the experiment. We cite two examples to illustrate how informative the simulation can be.

First, Fig. 10 shows the concentrations of several of the molecular products as functions of the time after the x-ray machine is turned on. The glycylglycine concentration is 
$0.05 \mathrm{M}$. At early times, the product concentrations build up at a constant rate, all of the products being formed in the intratrack reactions of the individual electrons produced by the $\mathrm{x}$ rays. Depending on the rate constants and diffusion constants of the precursors, track overlap begins to occur at about $10^{-2}-10^{-1} \mathrm{~s} ;$ and intertrack reactions take place. The slopes in Fig. 10 then rise and become parallel to the original slopes for the remainder of the time, $\geq 1 \mathrm{~s}$.

Second, Table 1 shows the fractions of some of the products that are made outside the tracks of individual electrons at $0.05 \mathrm{M}$ and $1.0 \mathrm{M}$. The rate constant for the reaction of $e_{\mathrm{aq}}$ with (GLY) ${ }_{2}$ to form ammonia is very large. None of the hydrated electrons escape from the vicinity of the electron tracks where they are originally produced. (At $0.01 \mathrm{M}$, however, some are able to escape.) Formation of succinic acid requires the dimerization of two deamination radicals. Since these radicals react with glycylglycine, succinic acid formation is depressed by increasing solute concentration (Fig. 9). Table 1 reflects quantitatively the way in which the deamination radical is scavenged by the solute at $1.0 \mathrm{M}$ before it can participate in intertrack reactions. As a result, its overall yield decreases with increasing $(G L Y)_{2}$ concentration. 
summary

We have reviewed our research over the past two decades on the development of Monte Carlo track-structure codes for calculations of radiation transport and energy deposition in aqueous solutions. After the investigations of the physical interactions with pure water, the studies were extended to -treat the formation of radicals and molecular species and their chemical reactions in water. In the late 1980 s the work was further extended to analyze damage to biological molecules irradiated in aqueous solution. These investigations carried through for the first time a simulation of all events that occur from the initial physical interactions of radiation to the appearance of new radiolytic species with measurable chemical yields.

The "test-case" studies of measurements and calculations for glycylglycine led to a successful, detailed simulation and quantitative accounting of the radiation chemistry of this molecule. The Monte carlo simulation, coupled with experimental measurements, offers a powerful approach to understanding mechanisms and pathways of radiation damage to biological molecules. Our next objective is the study of oligonucleotides and double-stranded segments of DNA in aqueous solution. 


\begin{tabular}{|c|c|c||}
\hline \multicolumn{3}{|c|}{$\begin{array}{c}\text { Table 1. } \\
\text { outside individual tracks. }\end{array}$} \\
\hline & & $1.00 \mathrm{M}$ \\
\hline Product & $0.05 \mathrm{M}$ & 0.000 \\
\hline & & 0.994 \\
\hline $\mathrm{NH}_{3}$ & 0.000 & 0.002 \\
\hline $\mathrm{N}_{2}$ Suc & 0.999 & 0.115 \\
\hline Suc & 0.584 & 0.998 \\
\hline Asp & 0.940 & \\
\hline AcG & 1.000 & \\
\hline & & \\
\hline & & \\
\hline & &
\end{tabular}




\section{References}

1. R. H. Ritchie, R. N. Hamm, J. E. Turner, H. A. Wright, and W. E. Bolch. Radiation Interactions and Energy Transport in the Condensed Phase. In Physical and Chemical Mechanisms in Molecular Radiation Biology, W. A Glass anci M. N. Varma (eds.), pp. 99-135. Plenum Press, New York (1991).

2. C. E. Klots, R. N. Hamm, H. A. Wright, and J. E. Turner. Non-homogeneous Kinetics in Irradiated Matter: An Appraisal of Computational strategies. Radiat. Prot. Dosimetry 31:29-31 (1990).

3. J. E. Turner, R. N. Hamm, H. A. Wright, R. H. Ritchie, J. L. Magee, A. Chatterjee, and W. E. Bolch. Studies to Link the Basic Radiation Physics and Chemistry of Liquid Water. Radiat. Phys. Chem. 32:503-510 (1988).

4. R. N. Hamm, J. E. Turner, R. H. Ritchie, and H. A. Wright. Calculation of Heavy-Ion Tracks in Liquid Water. Radiat. Res. $104:$ S-20-S-26 (1985).

5. J. E. Turner, J. L. Magee, H. A. Wright, A. Chatterjee, R. N. Hamm, and R. H. Ritchie. Physical and Chemical 
Development of Electron Tracks in Liquid Water. Radiat. Res. 96:437-449 (1983).

6. C. D. Jonah, M. S. Matheson, J. R. Miller, and E. J. Hart. Yield and Decay of the Hydrated Electron from 100 ps to 3 ns. J. Phys. Chem. 80:1267-1270 (1976).

7. C. D. Jonah and J. R. Miller. Yield and Decay of the $O H$ Radical from 200 ps to 3 ns. J. Phys. Chem. 81:1974-1976 (1977) .

8. T. Sumiyoshi and M. Katayama. The Yield of Hydrated Electrons at 30 Picoseconds. Chem. Letters 1887-1890 (1982) .

9. J. A. LaVerne and S. M. Pimblott. Scavenger and Time Dependences of Radicals and Molecular Products in the Electron Radiolysis of Water: Examination of Experiments and Models. J. Phys. Cheni, 95:3196-3206 (1991).

10. J. E. Turner, H. G. Paretzke, R. N. Hamm, H. A. Wright, and R. H. Ritchie. Comparative Study of Electron Energy Deposition and Yields in Water in the Liquid and Vapor Phases. Radiat. Res. 92:47-60 (1982).

11. H. G. Paretzke, J. E. Turner, R. N. Hamm, H. A. Wright, and R. H. Ritchie. Calculated Yields and Fluctuations 
for Electron Degradation in Liquid Water and Water Vapor. J. Chem. Phys. 84:3182-3188 (1986).

12. H. G. Paretzke, J. E. Turner, R. N. Hamm, R. H. Ritchie, and $H$. A. Wright. Spatial Distributions of Inelastic Events Produced by Electrons in Gaseous and Liquid Water. Radiat. Res. 127:121-129 (1991).

13. W. M. Garrison. Reaction Mechanisms in the Radiolysis of Peptides, Polypeptides, and Proteins. Chem. Rev. 87:381$398(1987)$.

14. W. M. Garrison, H. A. Sokol, and W. Bennett-Corniea. Radiation Chemistry of Glycylglycine in oxygen-free Systems. Radiat. Res. 53:376-384 (1973).

15. W. E. Bolch, J. E. Turner, H. Yoshida, K. B. Jacobson, R. N. Hamm, and O. H. Crawford, submitted to Radiat. Prot. Dos. 


\section{Figure Captions}

1. Complete track of a $4-\mathrm{keV}$ electron calculated ith OREC. Each dot in these stereo views represents the position of a radiolytic species $\left(\mathrm{OH}, \mathrm{H}, \mathrm{e}_{\mathrm{Aq}}^{-}\right.$or $\left.\mathrm{H}_{3} \mathrm{O}^{+}\right)$at the times shown.

2. Time-dependent yields (G-value = number per $100 \mathrm{eV}$ ) of hydrated electrons and $\mathrm{OH}$ radicals from pulse radiolysis with high-energy electrons. Points show measurements ${ }^{(6-8)}$ and lines give the yields calculated with RADLYS.

3. Total inelastic and ionization inverse mean free paths (IMFP) as functions of electron energy used in the computer code MOCA for water vapor (dashed lines) and OREC for liquid water (solid lines). (Values apply to unit density in both phases.) (Ref. 12.)

4. Ratios of ionization cross section to total inelastic cross section as functions of energy for electrons in liquid water (solid curve) and water vapor (dashed curve). (Ref. 10.) 
5. Normalized single-collision energy-loss spectra for 5-keV electrons in watex vapor (dashed curve) and liquid water (solid curve). (Ref. 11.)

6. Frequency distributions of nearest-neighbor separation for inelastic events in the tracks of $100-\mathrm{eV}$ and $1-\mathrm{keV}$ electrons in water in the vapor (dashed curves) and liquid (solid curves) phases. The curve labeled $\mathrm{NN}$ is for the liquid without collective effects. See text. (Ref. 12.)

7. Calculated segment of the track of a $1-\mathrm{MeV}$ proton in liquid water with central portion displayed on a large scale in lower portion. Each dot represents the location of one of the reactive species $\mathrm{OH}, \mathrm{H}, \mathrm{e}_{\mathrm{aq}}$, or $\mathrm{H}_{3} \mathrm{O}^{+}$at $10^{-12} \mathrm{~s}$.

8. Central portion of track from Fig. 7 superimposed on double-helical pattern of DNA structure. See text.

9. Comparison of measured (points) and calculated (lines) yields of total ammonia, free ammonia, acetylglycine (ACG), diaminosuccinic acid $\left(\mathrm{N}_{2} \mathrm{Suc}\right)$, aspartic acid (Asp), and succinic acid (Suc) as functions of glycylglycine concentration. The yields were obtained for irradiation of oxygen-free aqueous solutions by $200 \mathrm{kV} x$ rays at a dose rate of $2.80 \mathrm{~Gy} / \mathrm{min}$. 
10. Calculated concentrations of aspartic acid (Asp), acetylglycine (ACG), diaminosuccinic acid $\left(\mathrm{N}_{2} \mathrm{Suc}\right)$, and succinic acid (suc) as functions of time for the irradiation of $0.05 \mathrm{M}$ glycylglycine. Slopes change at times when the overlap of radicals produced in the tracks of different electrons become important. 

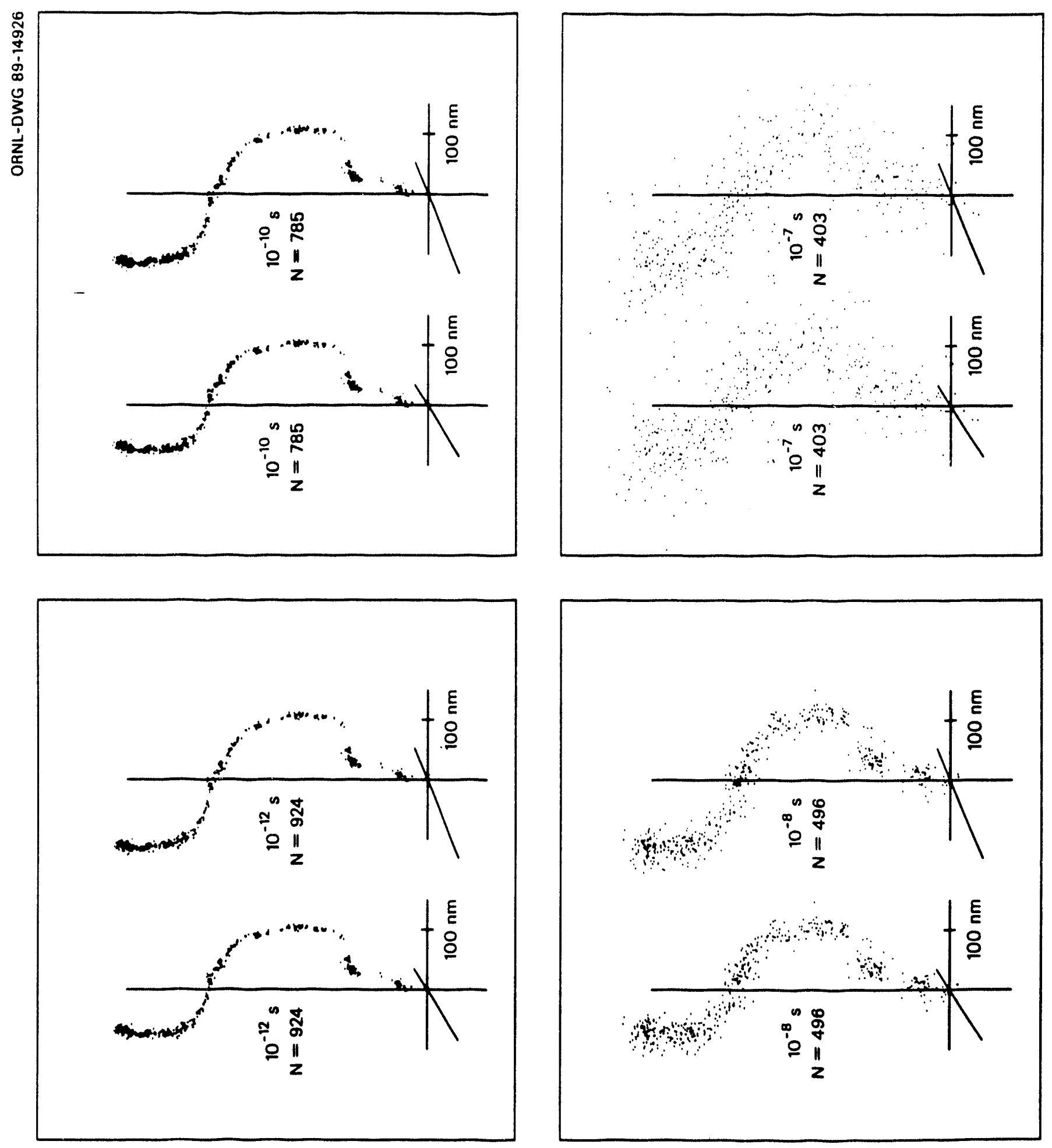

2 


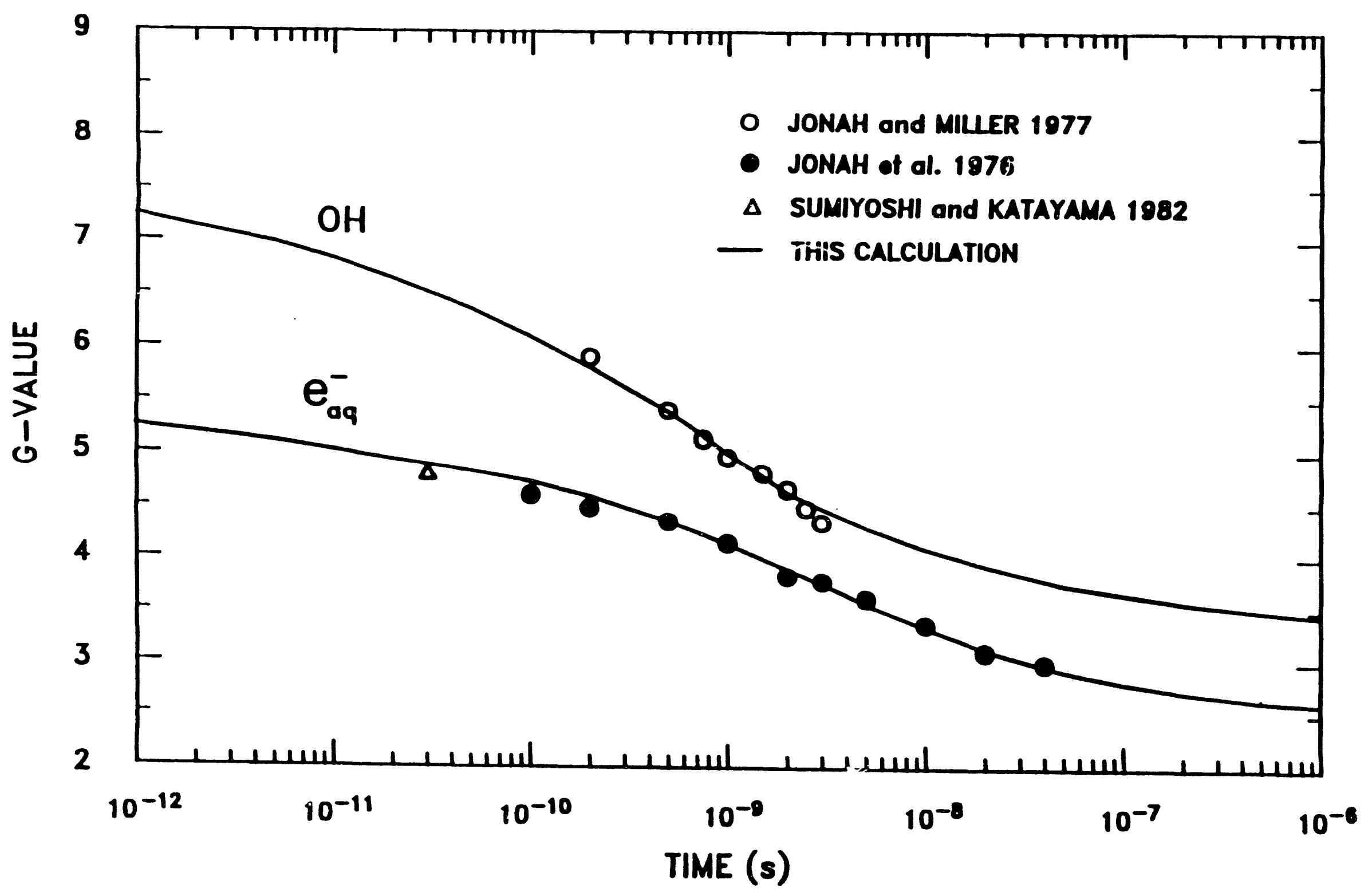

Turner, et al. Figure 2. 


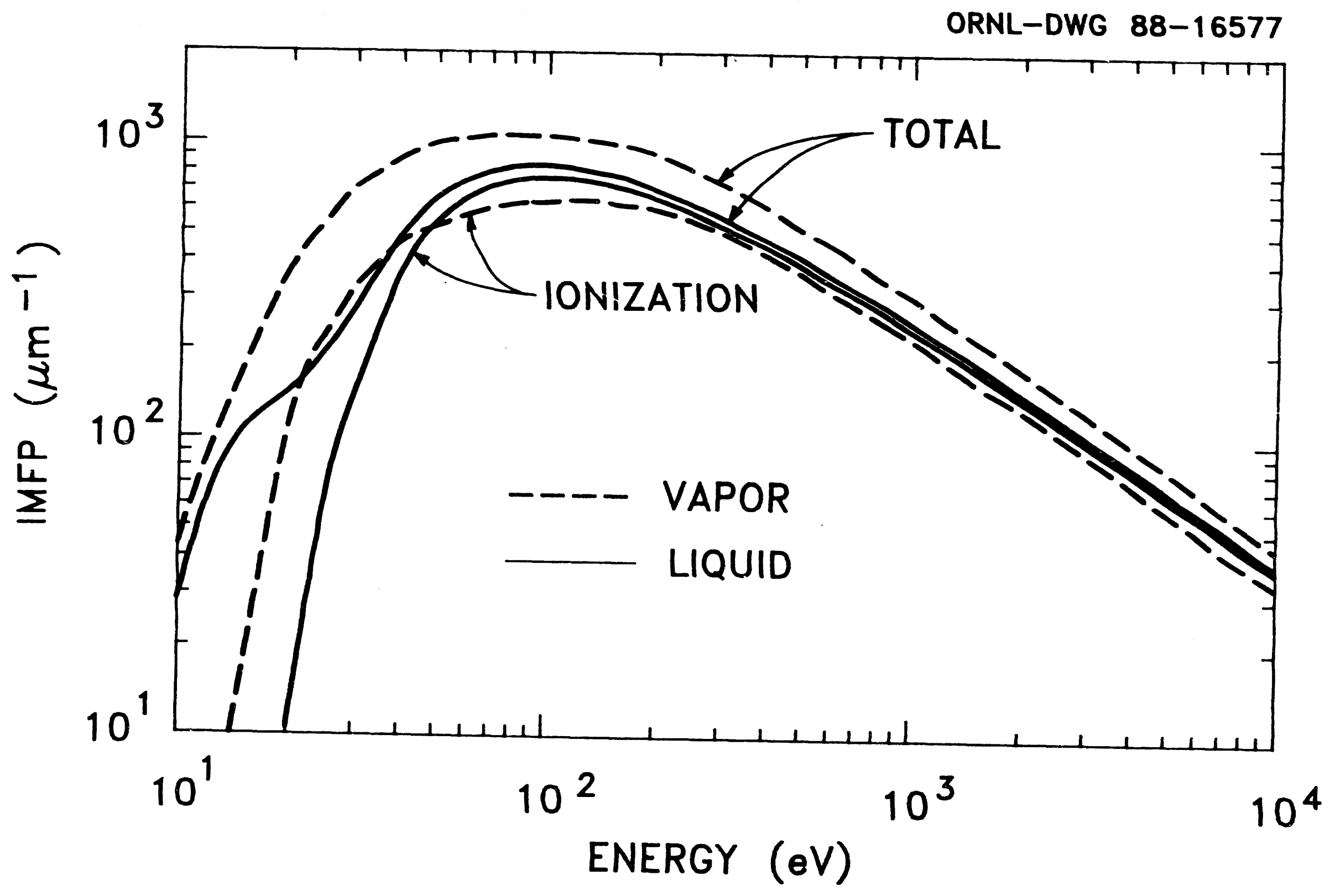

Turner, et al. 


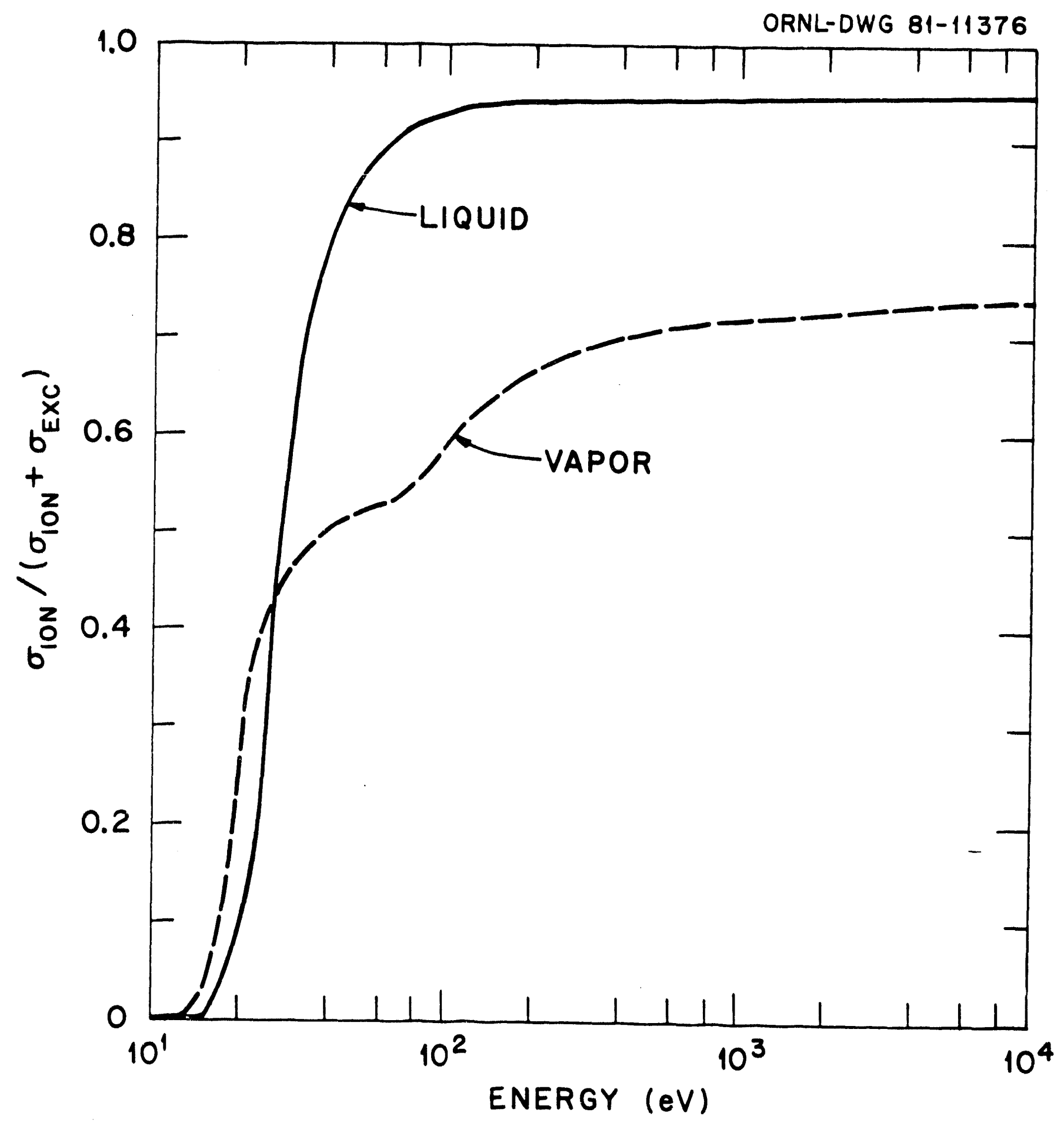




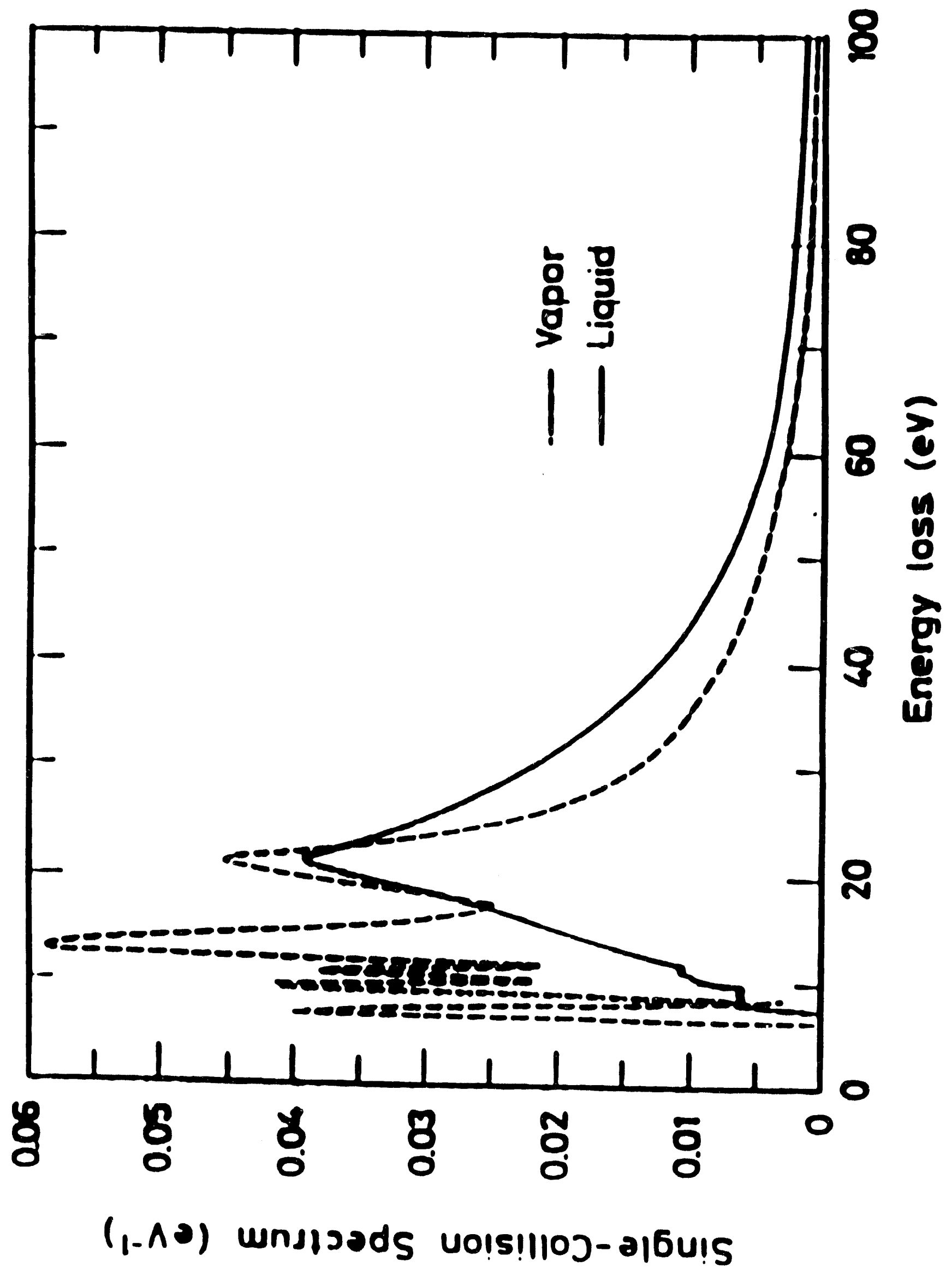




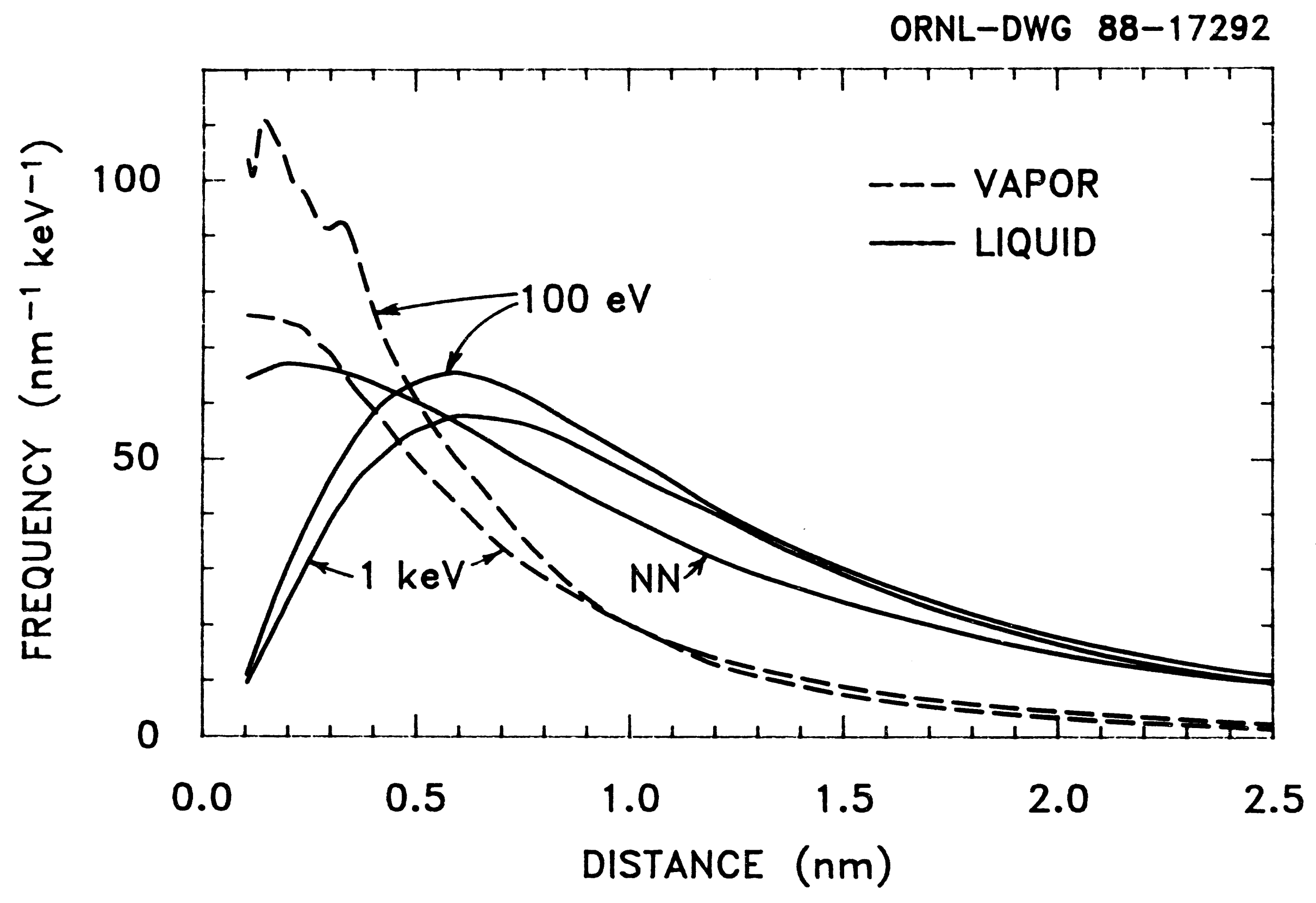

Turner, et al. Figure 6 . 
ORNL-DWG 85-10661

\section{1-MeV PROTON}

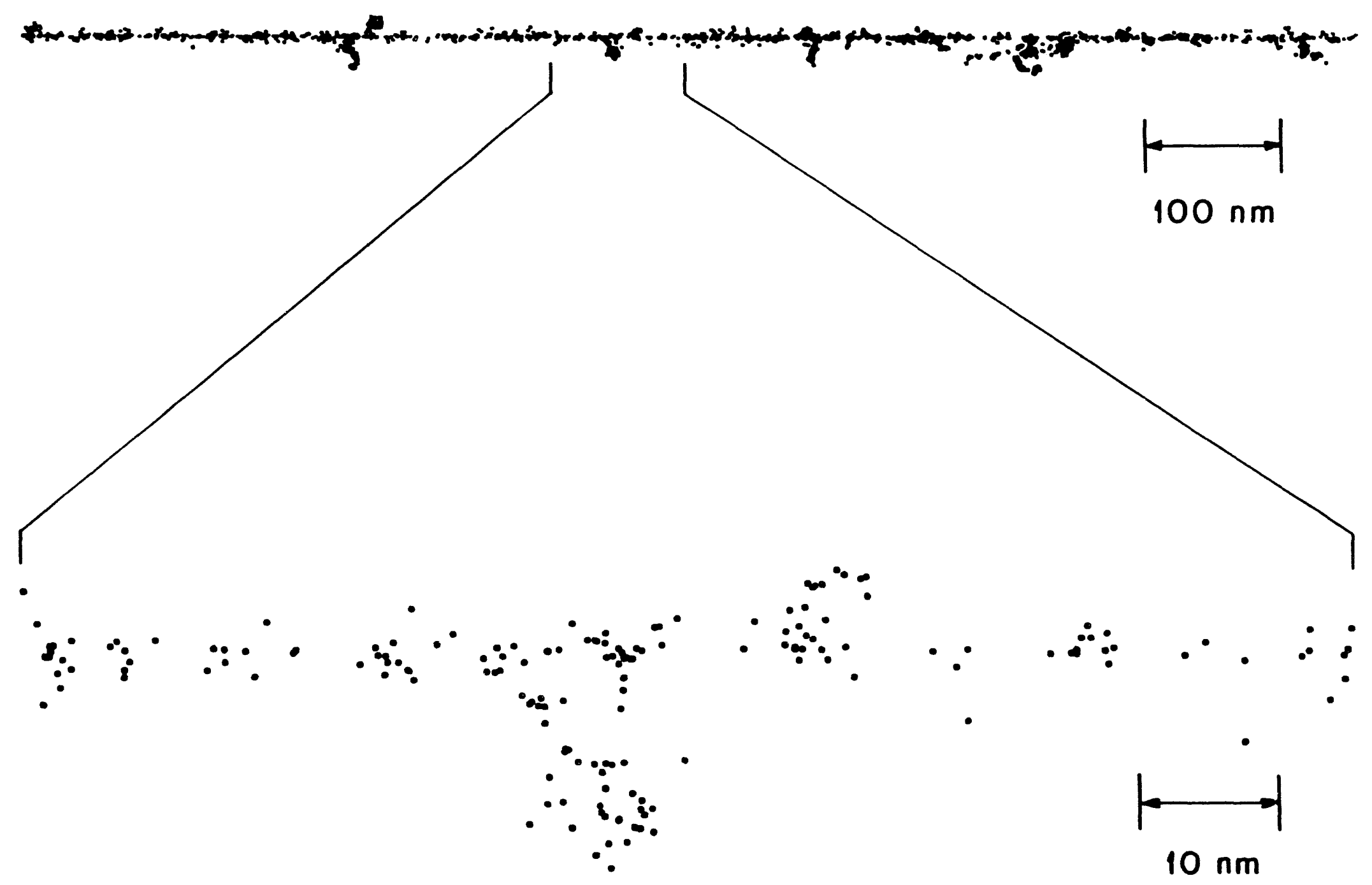

Turner, et al. Figure 7. 
0
0
0
0
1
10
0
0
3
0
1
2
2
0
0
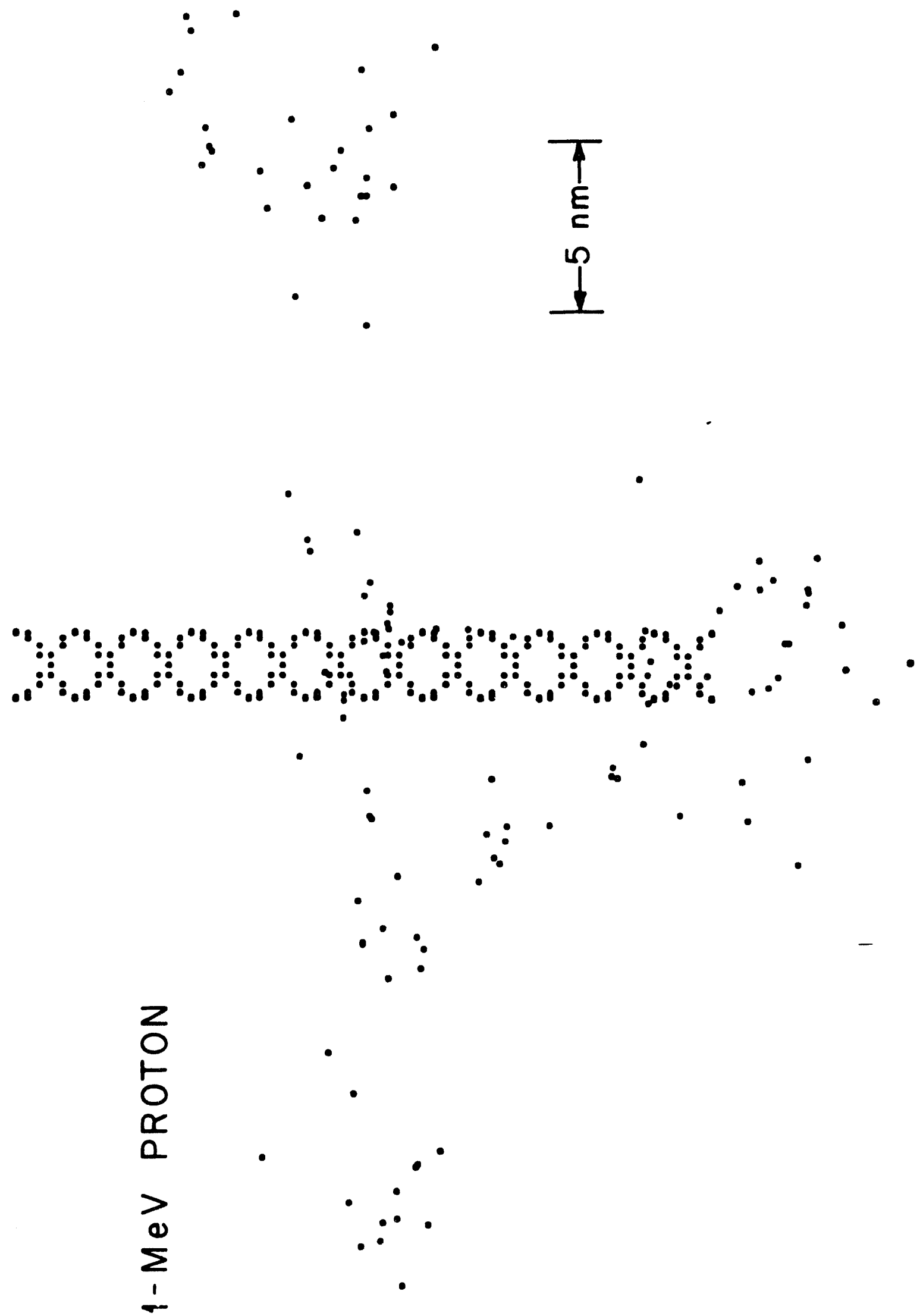


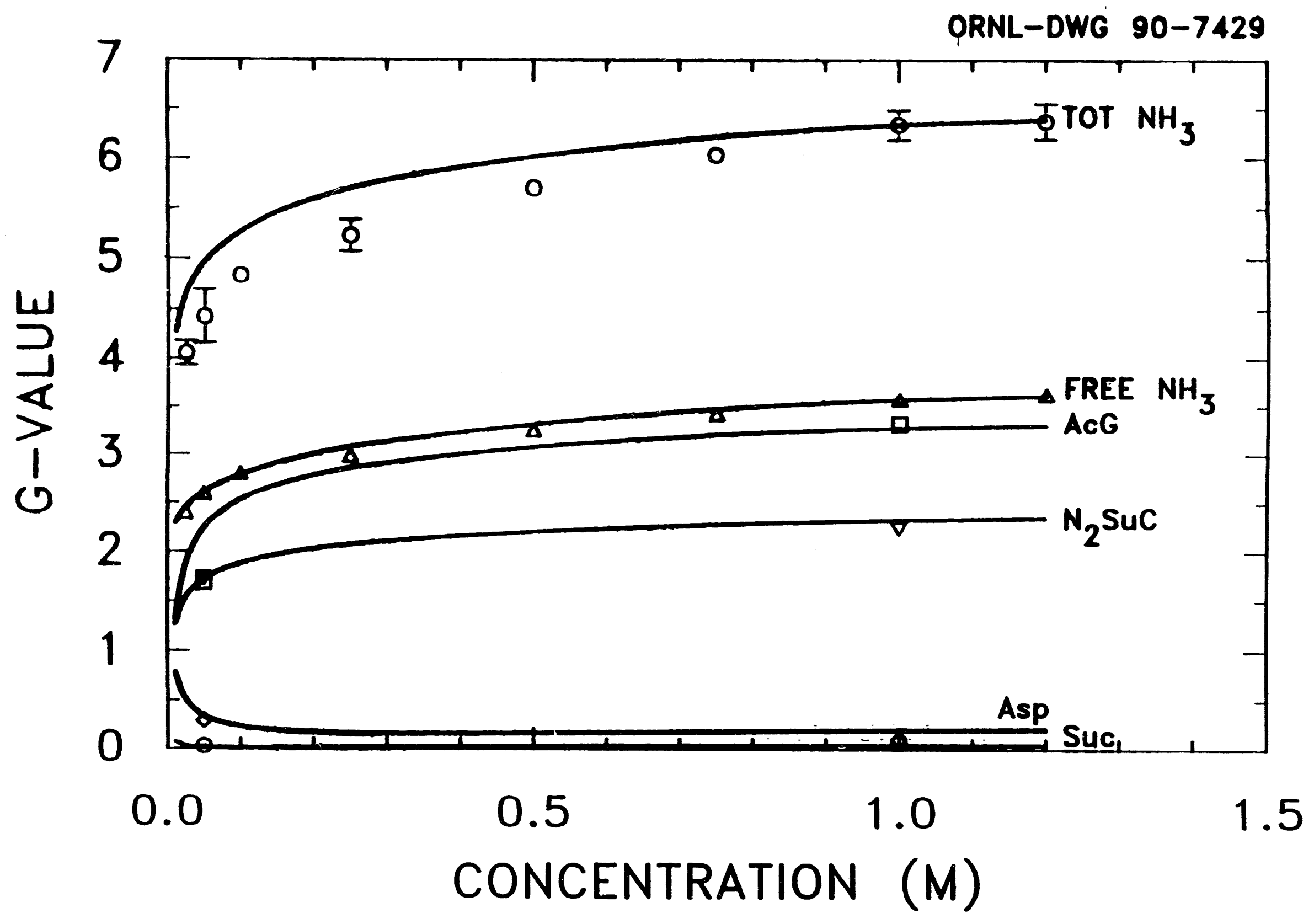


ORNL-DWG 90-9655

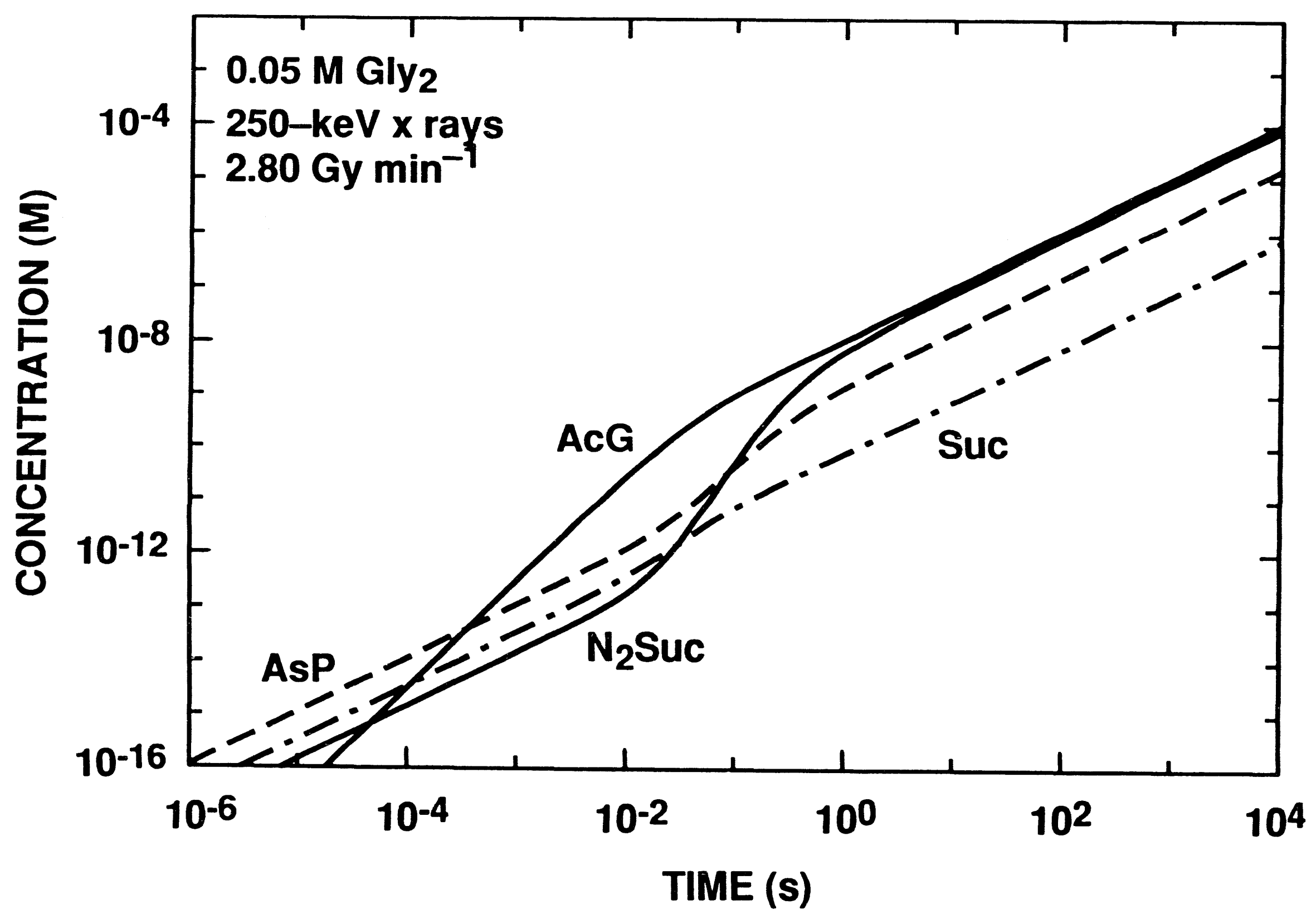



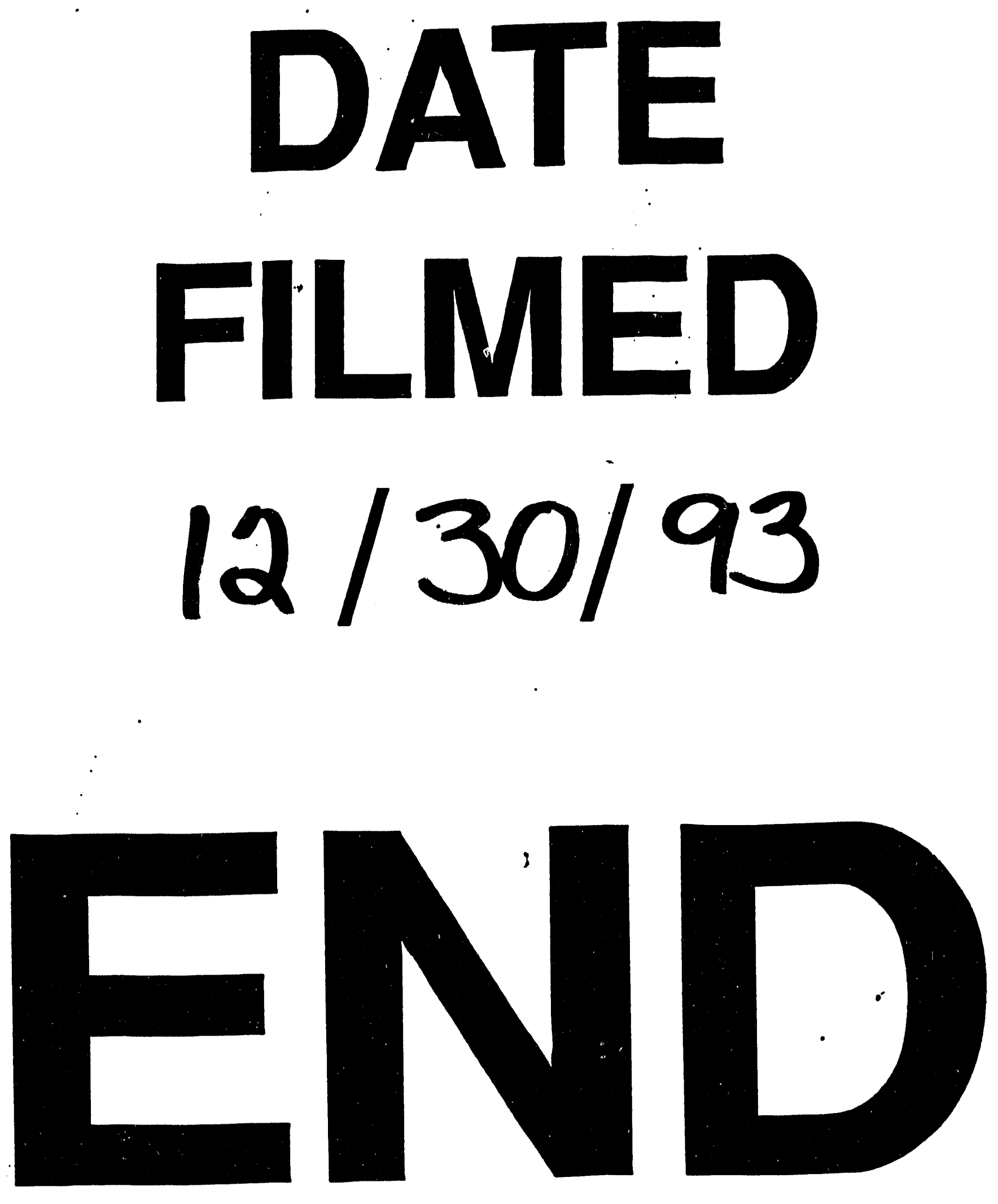
